\title{
Study on humanized design of intelligent charging device for electric bicycle
}

\author{
Shan liang $\mathrm{Yao}^{1}$, Man $\mathrm{Luo}^{2, \mathrm{a}}$ \\ ${ }^{1}$ EDP Sciences, Wuhan university of engineering, School of art design, China \\ ${ }^{2}$ EDP Sciences, Wuhan university of engineering, School of art design, China
}

\begin{abstract}
According to the analysis of the classification and demand of electric bicycle charging device, and combining with the humanized concept, we can discuss the design method of electric bicycle charging device. In order to produce electric bicycle way of humanized design of intelligent charging device moved by appearance, with emotion, pleasure from color as three kinds of expression way, based on the appearance and structure, function and operation, interface and detail from three aspects, physiological needs to the person's psychology and spirit pursuit are so important, we should show more respect and satisfy it, while the demands of users are coming. Users will feel more comfortable, while using this product, then they will have an emotion and dependence on product.
\end{abstract}

\section{Introduction}

As the most widely used transportation, Electric bicycle has advantages on both side of environmental protection and energy saving. On the other hand, we can see that its matching chargers per charge up to 7-8 hours. Once the battery run out of energy while driving, users will be in trouble. Electric bikes are bulky and extremely difficult to move. However, the demand of e-bike is so great, electric bicycle charging problem is badly in need of solving. Electric bicycle humanized design of the intelligent charging device should be guided by technology and function, concentrating on user needs. We need to add technology, function, color, shape, material and other factors into product humanized design, after analyzing and studying of user demands. This paper analyzes the humanized design through example of electric bicycle charging device and its design.

\section{Overview of electric bicycle charging device}

\section{1 classification of electric bicycle charging device}

According to different classification criteria, electric bicycle charging devices can be divided into different types.

(1) Classification of electric bicycle charging device.We can classify the charging form as two modes, mainly in the form of fast charge and slow charge, in needs of users. When the user is in urgent need of the car and the battery is too low, it is suitable for fast charging mode, which is generally applicable to slow filling mode.
(2) Classification by placement.According to the resettlement form of electric bicycle charging device, it mainly includes quick charging station, box-type charging pile and embedded charging pile.

(3) Classification by structural features. The charging station adopts a site assembly, and then the whole movement can be carried out like a container. The internal equipment is modular and equipped with special maintenance equipment for regenerative batteries.

(4) Classification by means of payment.In addition to traditional cash, the payment method also has the current popular mobile payment.

(5) Classification by application site.According to the electric bike users of the main activities of the regional classification, it can be divided into residential areas, public parking lots, high-speed service area, large shopping plaza, the company and office buildings, parking open side of the road.

\subsection{Demand analysis of e-bike charging device}

To improve the function of electric bicycle charging device according to the existing problems provided by users.

(1)Voice operation.Most of the existing charging devices in the market are charging stations and charging piles, which are large in size, and can have innovative designs in the shape, color and material of charging devices.

(2)Display function.User demand for charging device is not only the charging, also include in the process of using parking demand, payment, and so on, the demand of users and convenient lifestyle are also affect the charging device design, which we consider as a great innovation of design point. In this way, the charging 
device is not only a product, but also a convenient system for users to travel, changing the way people live.

(3) Automatic adjustment.Considering the age on using the crowd, level of education, and the health situation are different, the charging unit operation should be simple, fast, clear, using process can be implemented by means of animation simulation display or voice prompt to release.

(4) Cooling system. The existing charging unit lack of consideration on the performance of man-machine engineering, so the innovation of the charging device design man-machine performance indicators should be comprehensive consideration, and on the basis of existing data and real-time test data to correct.

\section{Humanized design of intelligent charging device for electric bicycle}

In the process of electric bicycle intelligent charging device design based on the needs of people, human physiological and psychological characteristics, following the principle of respect and care, meeting the user in the physical, mental, physical, psychological aspects of requirements. To take the advantages of artificial intelligence to create a safe, comfortable, efficient electric bicycle intelligent charging device as the goal. Electric bicycle intelligent charging device design of human nature is the designer of form and function of "human" factor of injection, products with "human nature is changed" character, has the emotion, personality, temperament and life.

\subsection{Expressions}

The humanized expression of the intelligent charging device of electric bicycle means to carry and embody the invisible spiritual form in tangible material form. Generally speaking, there are three kinds of humanized expressions ( table 1):

(1) Break the form design of the existing charging device on the market, through to the intelligent charging device modelling, colour, material, texture, such as the change of shape elements, bring psychological feelings and emotional experience to the user, namely "moved by appearance";

(2) With the design of product function development and mining, that an increasingly perfect the function and performance optimization of permeability in the process of the designer's personal feelings as well as to the care of the vulnerable group, make users feel more comfortable, convenient, make the person feel kind, warm and humanitarian care, respect just meet the demand of the people's physical and spiritual pursuit, namely "with emotion";

(3) A proper color for the interface will often become the finishing touch of the design, which comes from the deep processing of the interface and details, that is, " pleasure from color".
Table 1. The humanized design expression of electric bicycle intelligent charging device.

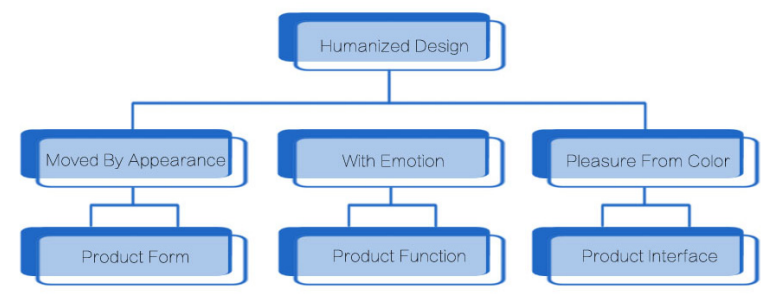

\subsection{Design principles}

Electric bicycle intelligent charging device design should be comprehensive with consideration of user requirements, technical support, material technology and so many other factors, there are huge differences between the humanized design of the electric bicycle intelligent charging device and the traditional charging device. Here comes the following design principles:

(1) Multi-functional design. Charging electric bicycle travel daily to remove this basic demand, is also important to stop a, and therefore should be integrated in the development of intelligent charging device design integration of multiple functions such as charging and parking, in order to effectively solve the user in the usual life of electric bicycle is disorderly parking place and charging the inconvenience;

(2) Green design. Electric bicycle intelligent charging device in design, saving of energy and materials should be considered, and the charging device material can choose in the recycling and facilitate the processing of materials, choose a kind of classic and timeless design on modelling, or by changing a few key components can be easily updated style, so as to prolong the service life of relative charging unit, achieve the goal of saving.Its payment method is paid offline by the device equipped with the app, which reduces the use of the real money and is another embodiment of green design.

(3) System design.Electric bicycle intelligent charging device solved a series of problems of the users in the daily, such as parking, charge, charge, weather, etc., to perfect on the function to the home from the trip to every step, is a set of system design.At the same time, the future business process of the intelligent charging device also has a relatively perfect specification, so that the product has a strong practical operation and becomes the user's intelligent travel steward.

\section{Design example of intelligent charging device for electric bicycle based on human nature}

\subsection{Humanized design with attractive appearance and structure}

Humanized design and product design are complementary and mutually reinforcing. The development of product design requires humanization, 
while humanized design needs the support of product design. Therefore, in the design, we not only seek the unity of beauty and practicality, but also seek the coordination of products and people and environment. This electric bicycle intelligent charging device abandons the common charging station appearance, charging pile on market with large volume, molding machine, and they are really not harmony with the surrounding environment, which is just designed by simple geometric shapes. Due to combined with charging the design of the device to lock the car in the parking lot, the lock and the charging device are just matched. At that time, the scene electric bike in a mess will pass away, the phenomenon such as security, reduces the waste of space, save material will come to us, and in the parking lot this particular environment, the charging device is subject to the environment, not only into the environment, also played the importance to the role of the environment, to achieve product consistent results in harmony with the environment. The overall design orientation is very strong, with neutral color as the main tone, and color on the details, which can remind the user.
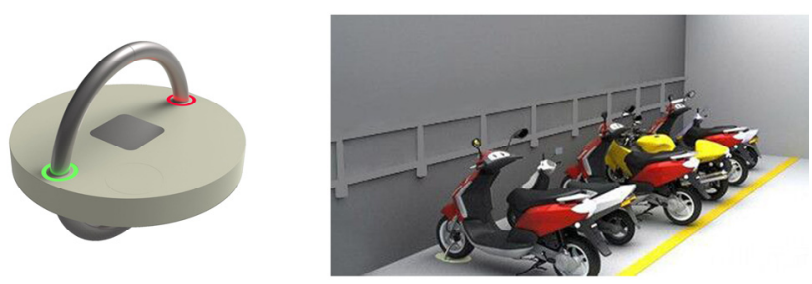

Figure 1. Below the figure.intelligent charging device and parking space of electric bicycle.

\subsection{Humanized design of function and operation with emotion}

This electric bicycle into the intelligent charging device lock the car with multiple functions such as charging, using induction pressure plate is connected to the lock switch, when the device is still, switch will be closed, the charger contraction; When the electric bicycle wheel comes into contact with the device, the lock will open automatically according to the pressure and displacement direction; When the electric bicycle is parked, it will not move for a period of time, and the sensor pressure plate will not feel the change of pressure, then the lock will open automatically. At the same time, the charge line cover will be opened, and the charging cable can be freely telescoped by the spring line to recharge the electric bicycle. In addition,the function of charging device development and mining embodied humanistic care, parking information, positioning function, charging real-time feedback, additional features such as weather forecast will be added to the main body of charging device functions. Combining the main function with a matched app makes the product a completely reasonable device, which makes the function of the products more perfect, more convenient to users in every way out, solves the electric bicycle charging inconvenience, disorderly parking in residential area and a series of problems. It will be intelligent housekeeper in travels. Due to the perfection and humanization design of the device, the user is quite convenient in operation, for example, the voice prompt function of the intelligent charging device facilitates the operation of the user.

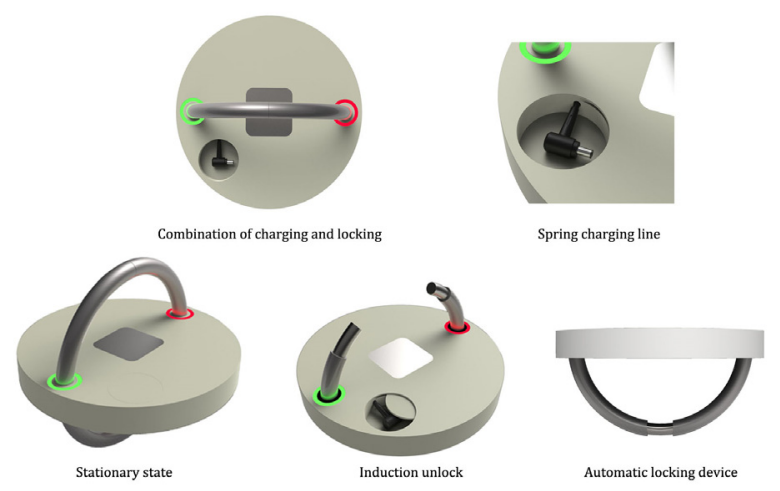

Figure 2. Function diagram of intelligent charging device for electric bicycle.

\subsection{The humanized design for the user - interface and details}

Electric bicycle charging device should pay attention to man-machine interface and detail design, and ensure the operation more accuracy, efficiency and comfort for user. Different functions of the product buttons, knobs, and the layout of the operation panel and modelling has different design requirements. Product interface design fully embody the features of the product, such as charging icon design used in app charging interface is the shape of the electric bicycle charging line, then the user will be clear at a glance while using. In the matched app, its interface is concise, clear, charging device in addition to meet the parking charge and the two main functions without redundant design, also do not have too much decoration and color processing. Locked and unlocked as two states, which is designed into red and green to enhance display effect. The interface design of the supporting app adopts the fresh green, which gives the user a comfortable experience, and echoes the green transportation tool of electric bicycle.

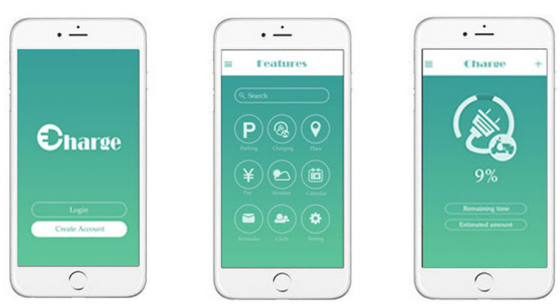

Figure 3. Main app interface of the smart charging device of electric bicycle.

\section{Conclusion}

The development and change of e-bike is not only driven by technology, but also by solving existing problems as an important force, as well as the design of external 
product charging device. The designer should pay attention to the object of the service, not only focus on the comfort level of product use, but also pay attention to the psychological satisfaction, and follow the trend of the current fashion. Then making a design maximally meets the needs of users, reflects electric bicycle charging unit, man-machine relationship, form and function, while using. Psychological aspects of the concern for people with respect, makes every effort to electric bicycle travel way of life, emphasize life, individuation, make electric bicycle intelligent charging device fully embodies the humanized design.

\section{References}

1. $\mathrm{P}$ qian, L zijian, $\mathrm{S}$ xia. Research on $\mathrm{SOHO}$ office furniture system design based on humanized concept ,Furniture and interior decoration. (2009)

2. S hui, H mi, Research on innovative design of bathroom products based on kansei engineering, Packaging engineering.(2011)

3. S miao. Exploration and research on humanized design in medical device products, Packaging engineering.(2007)

4. $\mathrm{G}$ wenzi,Design of an electric bicycle reverse charging device , China manufacturing informatization.(2011)

5. $\mathrm{N}$ shao qiang.,Design history and theoretical research: inheritance and development.(2007)

6. S zhiguo, Research on teaching and application of integrated equipment for the storage and charging of electric bicycles,Electromechanical information.(2017)

7. Donald a. Norman. Design psychology [M]. Xiao ke, translated. Citic press.(2015)

8. [8] jia xiaoxia. Analysis and visualization of user behavior based on e-bike data [D]. Zhejiang university.(2017) 